Goldschmidt 2021 Abstract

https://doi.org/10.7185/gold2021.6414

\title{
Finding the source following Sano
}

\section{TOBIAS P. FISCHER}

University of New Mexico

Presenting Author: fischer@unm.edu

Yuji Sano's work was among the first to quantify how much $\mathrm{CO}_{2}$ in arc gases is sourced from carbonates and organic sediments on the subducting slab versus the mantle wedge $[1,2]$. His approach of combining $\mathrm{CO}_{2}{ }^{\beta} \mathrm{He}$ with stable isotopes provided a technique to untangle reservoirs of carbon. Allard [3] had shown that $\mathrm{CO}_{2}$ in arc gases has a non-mantle signature and it was Marty and Jambon [4,5] that, in collaboration with Sano, examined systematically the gas emissions from Japan to quantify these sources. Expanding this approach to nitrogen and sulfur showed that the subducted slab is a major contributor of these volatiles to arc magmas. With improving gas flux estimates, our understanding of the global carbon, nitrogen and sulfur cycles continues to improve. Sano's work showed that collecting samples in the right location is critical for making informed interpretations of volatile sources. Realizing that helium isotopes decrease with distance from the crater [6] and that values vary with volcanic activity helps target the best sampling localities. Recent work utilizing clumped isotopes highlights the importance of identifying sites that have minimal air contamination to characterize the deep source [7]. Quantifying the contributions of the arc crust to volcanic gas discharges remains challenging. For carbon, systematic variations of ${ }^{3} \mathrm{He} /{ }^{4} \mathrm{He}$ with $\delta^{13} \mathrm{C}$ have been interpreted as the result of $\mathrm{CO}_{2}$ released from crustal carbonates significantly contributing to the volcanic arc volatile budget [8]. While more than enough carbon gets subducted to account for arc volcanic gas output, comprehensive global studies are needed to compare in detail slab geochemical characteristics with arc gases.

1. Sano, Y. and B. Marty, 119: p. 265-274.

2. Sano, Y. and S.N. Williams, Geophys. Res. Lett., 1996. 23(20): p. 2749-2752.

3. Allard, P. C.R. Acad. Sc. Paris, 1980. 290: p. 15251528.

4. Marty, B. and A. Jambon, EPSL, 1987. 83: p. 16-26.

5. Marty, B., A. Jambon, and Y. Sano, Chem. Geol., 1989. 76: p. 25-40.

6. Sano, Y., et al. 1990. 42: p. 41-52.

7. Labidi, J., et al. Nature, 2020. 580, : p. 367-371.

8. Mason, E., et al. Science, 2017. 357: p. 290-294. 